ORIGINAL ARTICLE

\title{
Postnatal growth retardation: a universal problem in preterm infants
}

\author{
R J Cooke, S B Ainsworth, A C Fenton
}

Arch Dis Child Fetal Neonatal Ed 2004;89:F428-F430. doi: 10.1136/adc.2001.004044

Background: Previous data from this unit suggest that postnatal growth retardation (PGR) is inevitable in preterm infants. However, the study was performed in a single level III neonatal intensive care unit and applicability of the findings to other level III or level I-II special care baby units was uncertain.

Objectives: To examine postnatal hospital growth and to compare growth outcome in preterm infants discharged from four level III tertiary care units and 10 level I-II special care baby units in the former Northern Region of the United Kingdom.

Subjects/methods: Preterm infants ( $\leqslant 32$ weeks gestation; $\leqslant 1500 \mathrm{~g})$ surviving to discharge were studied. Infants were weighed at birth and discharge. Body weight was converted into a $\mathrm{z}$ score using the British Foundation Growth Standards. To ascertain the degree of PGR, the $z$ score at birth was subtracted from the $\mathrm{z}$ score at discharge. Data were evaluated using a combination of split plot (level III $v \mathrm{l}-\mathrm{II}=$ main factor; individual centre $=$ subfactor) and stepwise regression analyses. Results were considered significant at $p<0.05$.

Results: A total of 659 (level III, $n=335$; level I-II, $n=324$ ) infants were admitted over a 24 month

See end of article for authors' affiliations

....................

Correspondence to: Dr Cooke, Newborn Center, University of Tennessee, Center for Health Sciences, Memphis, TN 38163, USA; rcooke@ utmem.edu

Accepted 20 January 2004 .................... period (January 1998-December 1999). No differences were detected in birth characteristics, CRIB score (a measure of illness in the first 24 hours of life), length of hospital stay, weight gain, weight at discharge, or degree of PGR between infants discharged from level III and level I-II units. Significant variation was noted in length of hospital stay ( 35\%; $p<0.001)$, weight gain $(\sim 33 \% ; p<0.001)$, weight at discharge $(\sim 20 \%$; $p<0.001)$, and degree of PGR $(\sim 200 \%$; $<<0.001)$ between the level III units. Even greater variability was noted in the duration of hospital stay $(\sim 40 \%$; $<0.001)$, weight gain $(\sim 60 \% ; p<0.001)$, weight at discharge $(\sim 40 \%, p<0.001)$, and degree of PGR $(\sim 300 \%, p<0.001)$ between the level I-II units.

Conclusions: These data stress the variable but universal nature of PGR in preterm infants discharged from level III and I-II neonatal intensive care units and raise important questions about nutritional support of these infants before and after hospital discharge.

$\mathrm{b}$

mpaired fetal and postnatal growth in term infants have been related to a higher risk of ischaemic heart disease, impaired glucose tolerance and type II diabetes mellitus, and higher blood pressure. ${ }^{1}$ These observations have critical implications for preterm infants who are commonly undergrown at birth and in whom the timely provision of an adequate dietary intake is limited because of immaturity and clinical instability.

Very few contemporary data are available on postnatal growth in preterm infants in the United Kingdom. ${ }^{23} \mathrm{~A}$ prospective evaluation of dietary intake and growth has suggested that postnatal growth retardation is inevitable in preterm infants; the more immature the infant, the greater the degree of postnatal growth retardation. ${ }^{3}$ However, patient populations and feeding practices differ, and what is applicable in one level III neonatal intensive care unit may not be applicable in another. Whether postnatal growth is different in infants discharged from level III intensive care units, which take care of the smallest sickest infants, and those discharged from level I-II special care baby units, which take care of more mature, less ill infants, has also not been determined.

The purpose of this study was to examine postnatal growth in preterm infants discharged from all units in the Northern Region in the United Kingdom. It was hypothesised that growth between birth and hospital discharge would $(a)$ be poorer in infants discharged from the level III intensive care units when compared with level I-II units and $(b)$ not differ between infants discharged across level III intensive care or infants discharged across level I-II special care baby units.

\section{SUBJECTS/METHODS}

Neonatal intensive care within the former Northern Region of the United Kingdom, an area serving 32000 deliveries/year, is provided by four tertiary care level III intensive care centres and 10 level I-II special care baby units functioning on a collaborative basis. Since 1995, a common database has been established for all babies admitted to the level III units. Since 1998, a minimum data set has been collected for all infants $\leqslant 32$ weeks gestation and $\leqslant 1500$ g birth weight admitted to the 10 level I-II units.

Data are prospectively and continuously collected from the level III units (North Tees, Sunderland, South Cleveland, Royal Victoria Infirmary) and the level I-II units (Whitehaven, Carlisle, Dryburn, North Tyneside, South Tyneside, Hartlepool, Darlington, Gateshead, Ashington, and Bishop Auckland). Data are entered by one person in each unit, then transmitted and collated centrally and double checked for accuracy by a single person (ACF).

This study included all surviving infants with a gestation of $\leqslant 32$ weeks or a birth weight of $\leqslant 1500 \mathrm{~g}$ discharged home from the level III and I-II units between I January 1998 and 31 December 1999 (24 months). Infants with a congenital or chromosomal anomaly were excluded from the study. For the purposes of this study, data pertaining to date of birth, birth weight, gestational age at birth, sex, clinical risk index for 
babies (CRIB) score (an index of severity of illness in the first few days of life), ${ }^{4}$ date of hospital discharge, and weight at hospital discharge were collected.

To control for variation in gestational and postnatal age, body weight was converted into a z score using the British Foundation Growth Standards. ${ }^{5}$ To ascertain the degree of postnatal malnutrition, the $\mathrm{z}$ score at birth was subtracted from the $\mathrm{z}$ score at discharge. Data were evaluated using a combination of analysis of variance, split plot (level I-II $v$ III $=$ main factor; individual centre $=$ subfactor), and stepwise regression analyses. Results were considered significant at $\mathrm{p}<0.05$.

\section{RESULTS}

For ease of presentation, the results are expressed as mean plus or minus one standard deviation. Between 1 January 1998 and 31 December 1999, 659 infants (322 girls, 337 boys) were discharged from the level III $(\mathrm{n}=335)$ and level I-II $(n=324)$ units. Table 1 presents a comparison of the two populations. No differences were detected in birth weights, $\mathrm{z}$ score for weight at birth, gestational age at birth, or CRIB score between the two study populations. No differences were detected in duration of hospital stay, weight gain, weight at discharge, gestational age at discharge, z score for weight at discharge, or changes in z score between level III and I-II centres.

Figure 1 shows a comparison of infants discharged from the level III centres. Birth weight (1260 (322) to 1427 (299); $\mathrm{p}<0.05$; fig 1A) and gestational age at birth (29.6 (2.6) to 30.5 (2.2), $\mathrm{p}<0.05$; fig $1 \mathrm{~B}$ ) but not $\mathrm{z}$ score for weight at birth $(-0.52(1.3)$ to $-0.32(1.4) \mathrm{SD})$ or CRIB score $(2.2(3.1)$ to $2.4(2.8))$ varied somewhat between the units.

The duration of hospital stay (39 (18) to 55 (27) days; $\mathrm{p}<0.005$ ), weight gain during hospital stay (18 (7) to 24 (9) g/day; p < 0.0001), weight at discharge (2073 (442) to 2540 (597) g; p < 0.0001; fig 1A), gestational age at discharge ( 36.5 (1.7) to 37.5 (2.1) weeks; p < 0.001; fig 1B), and change in $\mathrm{z}$ score between birth and discharge $(-0.5$ (0.7) to -1.0 (0.9) SD; p $<0.0005$; fig $1 \mathrm{C}$ ) also varied between the level III centres.

Figure 2 shows a comparison of infants discharged from the level I-II centres. Birth weight (1249 (296) to 1438 (364) g), gestational age at birth (29.6 (1.8) to 30.2 (2.1) weeks), z score for birth $(-0.4$ (1.3) to -0.8 (1.0)) and CRIB score $(2.2$ (3.2) to 3.3 (3.6)) did not vary significantly between the units.

Yet, the duration of hospital stay (43 (17) to 63 (49) days; $\mathrm{p}<0.01$ ), weight gain during hospital stay (15 (6) to 24 (5) g/day; p $<0.001$ ), weight at discharge (1858 (251) to 2621 (927) g; p < 0.001; fig 2A), gestational age at discharge (36.1 (2.8) to 37.7 (3.4) weeks, p $<0.0005$; fig $2 \mathrm{~B}$ ), and

\begin{tabular}{|c|c|c|}
\hline & $\begin{array}{l}\text { Level III } \\
\text { ( } n=285)\end{array}$ & $\begin{array}{l}\text { Level I-II } \\
(n=324)\end{array}$ \\
\hline Birth weight (g) & $1324(320)$ & 1339 (324) \\
\hline Gestational age (w) & $30(2.5)$ & $30(2.1)$ \\
\hline$z$ score at birth & $-0.44(1.4)$ & $-0.29(1.3)$ \\
\hline CRIB score & $2.3(3.0)$ & $2.7(3.3)$ \\
\hline Weight gain (g/day) & $20(7)$ & $20(8)$ \\
\hline Hospital stay (days) & $49(28)$ & $51(30)$ \\
\hline Gestation at discharge & $37(3.2)$ & $37(2.8)$ \\
\hline z score at discharge & $-1.2(1.0)$ & $-1.2(1.2)$ \\
\hline Fall in $\mathrm{z}$ score & $-0.72(0.86)$ & $-0.86(0.85)$ \\
\hline
\end{tabular}
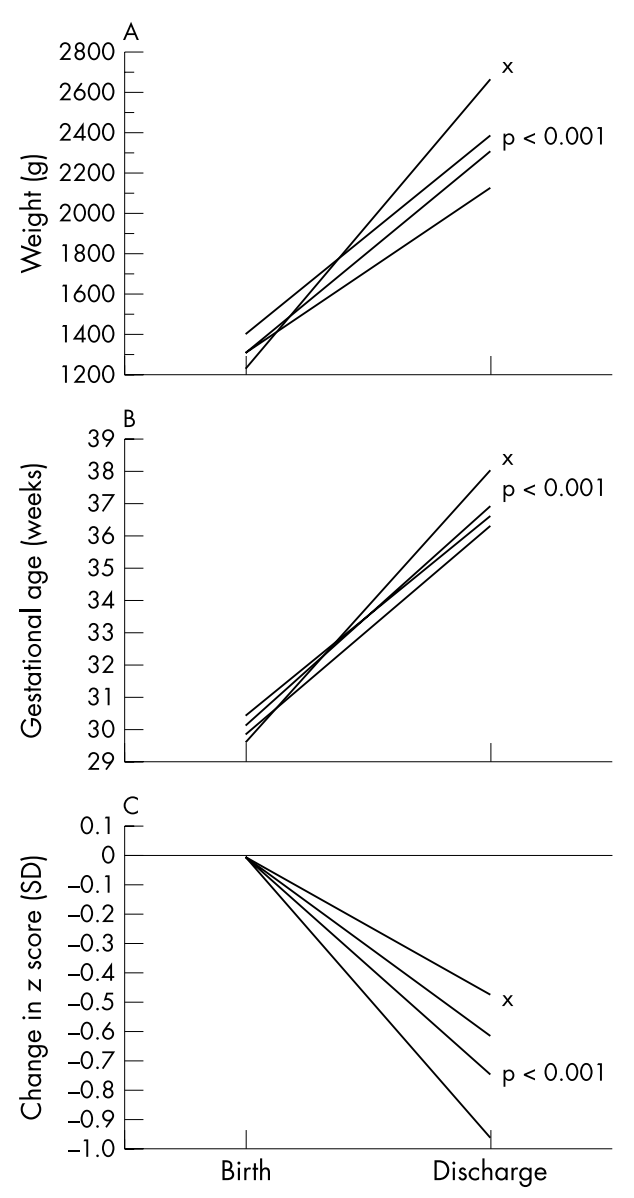

Figure 1 Comparison of infants discharged from level III units.

change in z scores $(-0.46(0.75)$ to $-1.3(1.0)$ SD; $p<0.005$; fig 2C) varied widely between the level I-II units.

Stepwise regression analysis indicated that variation in $\mathrm{z}$ score at birth, gestational age at birth, and CRIB score accounted for $\sim 45 \%$ of the variation in change in $\mathrm{z}$ score between birth and discharge $(p<0.001)$, irrespective of whether an infant was discharged home from a level III or I-II unit.

\section{DISCUSSION}

No differences were detected in birth characteristics, duration of hospital stay, or growth between infants discharged from level III and I-II units. This, perhaps, is surprising. Neonatal intensive care in the Northern Region is regionally delivered with high risk or sick infants transferred, either in utero or postnatally, from a level I-II to a level III unit, but as soon as it is clinically indicated infants are transferred back to the local I-II unit. The distinction between infants discharged from level III and I-II units therefore may have been more perceived than real.

Variation in postnatal growth between the four level III units is partly explained by differences in birth weight, $\mathrm{z}$ score, and gestational age at birth. The unit with the lowest birth weight and gestational age and z score at birth had the longest hospital stay and were heaviest at discharge (x; fig 1A). Increased length of stay partly explains increased weight at discharge because the longer a preterm infant formula is fed, the greater the weight gain and body weight at discharge. However, it is unlikely to explain the $\sim 200 \%$ difference in change in z score between birth and discharge between the level III units (fig. IC). 

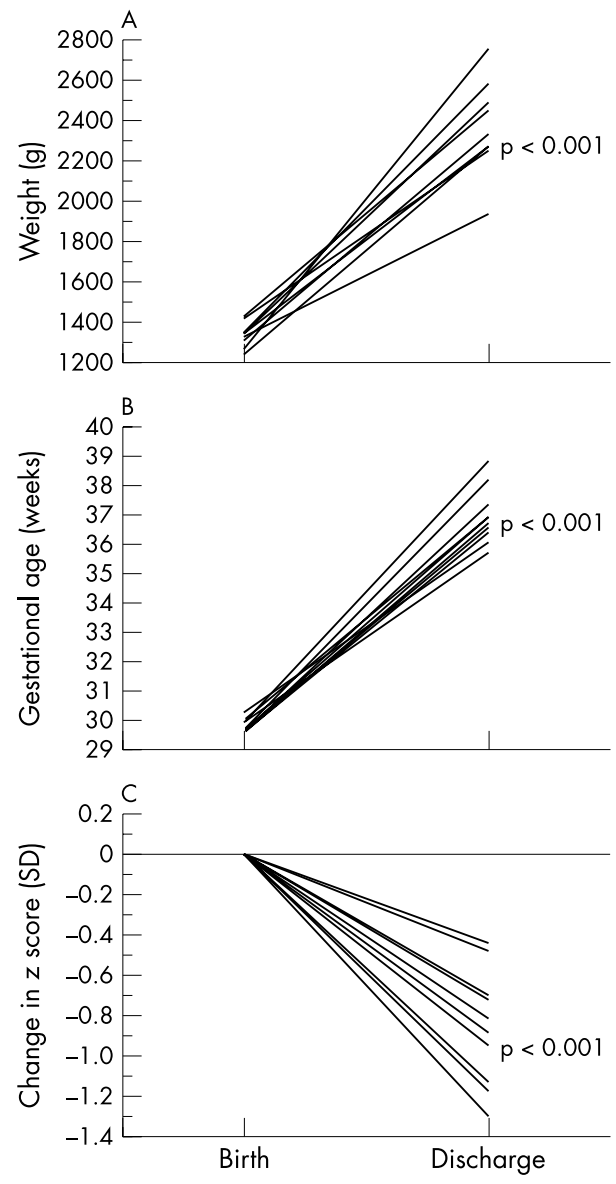

Figure 2 Comparison of infants discharged from level I-II units.

The variation in outcome between level I-II units is unexpected. No differences were detected in birth weight, gestational age, or z score at birth, but length of hospital stay and weight at discharge varied by $\sim 40 \%$. Again, a longer length of stay can be related to better weight gain and increased weight at discharge, but it also is unlikely to explain the $\sim 300 \%$ difference in change in z scores between birth and discharge between the level I-II units (fig. 2C).

Approximately $45 \%$ of the fall in z score was explained by variation in $\mathrm{z}$ score at birth, gestational age, and severity of illness during early life-that is, CRIB score. z score at birth and CRIB score did not differ in the four level III units. $\mathrm{z}$ score at birth, gestational age, and CRIB score also did not differ in the 10 level I-II units. Thus, differences in patient populations or severity of illness do not explain the differences in growth within the level III and within I-II units.
We have previously shown that $\sim 55 \%$ of variation in postnatal growth can be related to energy and protein intakes. ${ }^{3}$ In this study it was not possible to collect intake data in such a large group of infants $(n=659)$. It also was not possible to control for differences in discharge policies between the units. Nonetheless, if feeding practices and therefore nutrient intake varied, it would at least partly explain the wide variation in postnatal growth within the level III and I-II units. A further study is needed to examine this issue.

Nevertheless, the results of this study are important. Poor neonatal growth in preterm infants is directly related to poor growth at 1 and 3 years of age $\mathrm{a}^{6-8}$ and poor neurodevelopmental outcome. ${ }^{9-12}$ Recent studies suggest that growth can be improved by feeding nutrient enriched infant formulas to preterm infants after hospital discharge. ${ }^{13-15}$ Yet, such formulas are not readily available and/or fed to preterm infants after hospital discharge. Data from this study stress the universal nature of early postnatal growth retardation and the need for specialised nutritional support in these high risk infants during the first year of life.

\section{Authors' affiliations}

R J Cooke, S B Ainsworth, A C Fenton, Special Care Baby Unit, Royal Victoria Infirmary, University of Newcastle upon Tyne, UK

\section{REFERENCES}

1 Barker D. Fetal and infant origins of adult disease. BMJ 1990;301:1111.

2 McClure RJ, Newell SJ. Randomised controlled study of clinical outcome following trophic feeding. Arch Dis Child Fetal Neonatal Ed 2000;82:F29-33.

3 Embleton NE, Pang N, Cooke RJ. Postnatal malnutrition and growth retardation: an inevitable consequence of current recommendations in preterm infants? Pediatrics 2001:107:270-308.

4 Tarnow-Mordi W, Parry G. The CRIB score. Lancet 1993;342:1365.

5 Cole TJ, Freeman MA, Preece MA. British 1990 growth reference centiles for weight, height, body mass index and head circumference fitted by maximum penalized likelihood. Stat Med 1998;17:407-29.

6 Ernst JA, Bull MJ, Rickard KA, et al. Growth outcome and feeding practices of the very low birth weight infant (less than 1500 grams) within the first year of life. J Pediatr 1990; 117:S156-66.

7 Casey PH, Kraemer HC, Bernbaum J, et al. Growth patterns of low birth weight preterm infants: a longitudinal analysis of a large, varied sample. J Pediatr 1990;1 17:298-307.

8 Fenton TR, McMillan DD, Sauve RS. Nutrition and growth analysis of very low birth weight infants. Pediatrics 1990;86:378-83.

9 Gorga D, Stern FM, Ross G. Trends in neuromotor behaviour of preterm and fullterm infants in the first year of life: a preliminary report. Dev Med Child Neurol 1985;27:756-66.

10 Hack M, Horbar JD, Malloy MH, et al. Very low birth weight outcomes of the National Institute of Child Health and Human Development Neonatal Network. Pediatrics 1991;87:587-97.

11 Lucas A, Morley R, Cole TJ, et al. Early diet in preterm babies and developmental status in infancy. Arch Dis Child 1989;64:1570-8.

12 Lucas A, Morley R, Cole TJ, et al. Early diet in preterm babies and developmental status at 18 months. Lancet 1990;335:1477-81.

13 Lucas A, Bishop NJ, King FJ, et al. Randomised trial of nutrition for preterm infants after discharge. Arch Dis Child 1992;67:324-7.

14 Cooke RJ, Griffin IJ, McCormick K, et al. Feeding preterm infants after hospital discharge: effect of dietary manipulation on nutrient intake and growth. Pediatr Res 1998;43:355-60.

15 Cooke RJ, McCormick K, Griffin IJ, et al. Feeding preterm infants after hospital discharge: effect of diet on body composition. Pediatr Res 1999;46:461-4. 